\title{
BMJ Open A questionnaire study of the negative outcomes for UK health professional volunteers in low and middle income countries
}

\author{
Natasha Tyler (D) , ${ }^{1}$ Helen Louise Ackers, ${ }^{2}$ Anya Ahmed, ${ }^{3}$ Ged Byrne, ${ }^{4}$ \\ Lucie Byrne-Davis ${ }^{5}$
}

To cite: Tyler N, Ackers HL, Ahmed $A$, et al. A questionnaire study of the negative outcomes for UK health professional volunteers in low and middle income countries. BMJ Open 2020;10:e037647. doi:10.1136/ bmjopen-2020-037647

- Prepublication history and additional material for this paper are available online. To view these files, please visit the journal online (http://dx.doi org/10.1136/bmjopen-2020037647).

Received 13 February 2020 Revised 03 April 2020 Accepted 07 May 2020

Check for updates

(c) Author(s) (or their employer(s)) 2020. Re-use permitted under CC BY-NC. No commercial re-use. See rights and permissions. Published by BMJ.

${ }^{1}$ NIHR Greater Manchester Patient Safety Translational Research Centre, The University of Manchester, Manchester, UK

${ }^{2}$ School of Health and

Society, University of Salford, Manchester, UK

${ }^{3}$ Department of Social Care and Social Work, Manchester

Metropolitan University,

Manchester, UK

${ }^{4}$ Health Education England, Manchester, UK

${ }^{5}$ Manchester Medical School, University of Manchester, Manchester, UK

Correspondence to Dr Natasha Tyler; natasha.tyler@manchester. ac.uk

\section{ABSTRACT}

Introduction Past research has reported considerable benefits of international health professional volunteering for British healthcare professionals; however, there are also some negative outcomes reported. Negative outcomes reportedly happen on a personal, professional and organisational level. However, there is little evidence of the frequency they might occur.

Methods We aimed to understand what the negative outcomes of health professional volunteering in lowincome and middle-income countries were, and how frequently they occurred, in an opportunistic sample of UK health professionals. We used a questionnaire developed using potential negative outcomes reported in the peerreviewed papers. We conducted secondary analysis on cross-sectional questionnaire data from 222 healthcare professionals.

Results This research provides an indication of the frequency that negative outcomes might occur. Post hoc analyses revealed that some outcomes were experienced by the majority of health professional volunteers, for example, lack of formal recognition (131/169, 78\%) and financial cost $(92 / 169,68 \%)$. While others happened less, for example, a reliance on agency or locum work (12/169, $7 \%$ ) and loss of pension (31/169, 18\%).

Conclusion The outcomes reported in this research quantify some of the concerns that have been raised in previous literature. Negative outcomes might be associated with certain features of volunteering and further research is needed to prospectively compare different features. Organisers of volunteering opportunities should be aware of the potential negative outcomes and engage with the research into negative outcomes to generate and apply findings about minimising potential negative outcomes, carefully balancing these against the needs of the host country.

\section{INTRODUCTION}

Healthcare professionals sometimes participate in international placements in lowincome and middle-income countries (LMICs), this activity is often referred to as volunteering. The nature of international placements are varied ranging from 1-day training sessions to projects lasting 2 or more
Strengths and limitations of this study

This is the first study to quantify the potential negative outcomes of international volunteering experienced by UK health professionals.

- The sample includes health professional volunteers from numerous professional cadres, that visited over 50 different countries in various capacities on numerous projects.

- Some of the negative outcomes are open to interpretation and could be considered positive from another perspective (ie, leaving the UK health service to work in disadvantaged one).

- This study presents post hoc analyses so there were no planned comparisons, therefore our findings are only suggestive of hypotheses that need to be tested and not hypothesis testing themselves.

years. ${ }^{1}$ The purpose of the international placements also vary, for example, some focus on delivering a medical service, that is, after a natural disaster, while others focus on training or capacity building. ${ }^{1}$ Participating in international placements is predominantly described as a mutually beneficial experience for both the high-income health professional and professionals and patients in the lowincome and middle-income country. ${ }^{1-6}$ Our recent systematic review outlines the distinct educational benefits of this activity, and found 115 benefits spanning numerous domains, an improvement in communication, leadership and cultural development were frequently reported themes. ${ }^{4}$ While there is a growing evidence of such benefits and health professional volunteering is generally considered a positive experience, to date there has been little exploration of the negative outcomes that sometimes occur. ${ }^{4}$ With international placements being so varied, there is a requisite to develop a framework of potential negative outcomes to understand how and why 
they happen and develop methods to reduce them in the future.

While reported infrequently, negative outcomes are identified across many levels: personal, professional or organisational. On an organisational level, outcomes are proposed to have a negative effect on the NHS (National Health Service), trust or employer of the professionals undertaking the placements. For example, the cost of backfilling a staff member while they are overseas. ${ }^{7}$ Similarly, there is the non-financial element embodied in the human resource difficulties of finding cover for trained staff that temporarily or permanently leave posts. ${ }^{5}$

From a professional perspective, historically and even in the 90s undertaking international work was sometimes considered 'career suicide', through deviation from the prescribed training pathway. ${ }^{8}$ Despite increased popularity and efforts to move beyond this, some of the principle elements that initiated this opinion may still be relevant, particularly for medics who report difficulties with professional revalidation or securing permanent employment on return. ${ }^{9}{ }^{10}$ During international placements, an element of de-skilling is sometimes highlighted, professionals report a loss of clinical confidence, communication skills, knowledge and confidence using NHS systems like referrals, policy and good practice. ${ }^{11} 12$ There are also reports of people developing bad habits or redundant skills that are not applicable to the UK or one's career stage. ${ }^{9}{ }^{13}$ The most commonly reported negative outcomes extracted in the systematic review were a lack of recognition or accreditation for the work done. ${ }^{814-16}$ Other professional negative outcomes included pressure to work outside one's competence, ethical dilemmas, lengthening of training and bureaucratic barriers. ${ }^{917-19}$

Although uncommon, negatives outcomes exist from a personal perspective, including the tangible financial cost of undertaking an international placement. ${ }^{2}{ }^{9} 20$ The financial cost is not always immediate, professionals report effects on pensions, entitlements or loss of earnings. ${ }^{20} 21$ Travelling to a LMIC environment can also have health consequences, professionals report outcomes ranging from animal bites, to road traffic accidents, sexually transmitted diseases and stress. ${ }^{22} 23$ Other emotional and psychological outcomes include loneliness, missing family and frustration. ${ }^{519} 22$ Culture shock, the feeling of disorientation experienced by someone when they are suddenly subjected to an unfamiliar culture, is frequently reported. ${ }^{22} 24$ Similar outcomes include being involved in crime (as perpetrator or victim) and physical risk (eg, dangerous environments and extreme nationalism). ${ }^{12} 1726$

Past research has ${ }^{5}$ synthesised qualitative data regarding the costs of volunteering within NHS health partnerships (one of many types of volunteering involving a link between an LMIC partner institution and the UK trust). This research generated five domains related to cost/ negative outcomes: financial, loss of staff, reputational, health and security and opportunity. ${ }^{5}$ Other research has focussed predominantly on a single domain, for example, the health consequences of UK short-term volunteering placements. ${ }^{23}$ However, this did not concern health professionals or encompass a range of negative outcomes. Recent work has looked at the barriers to international volunteering for health professionals, while this is sometimes also a negative outcome it is just one component. ${ }^{27}$ Our previous work has discussed a number of negative outcomes, but there is no quantification of how often they occur. ${ }^{4}$ Therefore, whilst there is a list of potential negative outcomes that affect British health professionals on a variety of LMIC placements, there is not an indication of how often these occur and who is affected.

In summary, past research has reported considerable benefits of international volunteering, but it could be that negative outcomes are associated with certain types of placements. For example, a growing body of evidence suggests 'global health partnerships' between UK and LMIC organisations are one way of reducing some negative outcomes. Working beyond one's capacity, isolation, failure of re-integration and post-traumatic stress may be mitigated if the established co-development infrastructure is in place under a partnership model. ${ }^{2829}$ Therefore in order to understand how to maximise the benefit and reduce the negative outcomes, we must first understand specifically which negative outcomes have been reported. To our knowledge no other research has looked to list the types of negative outcomes that might occur and the frequency with which they occur. Therefore, in this paper we will (a) outline the negative outcomes reported in the peer-reviewed literature and (b) outline the frequency with which they were experienced by past health professional volunteers.

\section{METHODS \\ Study design}

We conducted a secondary analysis of a data collected using a cross-sectional questionnaire, the full methods are published elsewhere. ${ }^{30}$ The questionnaire that was administered to health professionals who had, or who would be, involved in international placements, at a single point in time which asked them to report whether they had experienced negative outcomes from international volunteering.

We assessed how frequently the negative outcomes included in the review ${ }^{4}$ were reported in an opportunistic sample of healthcare professionals on international placements. In the original paper, data were collected about both positive and negative outcomes, ${ }^{30}$ but the negative outcomes were not analysed.

This was an analysis of secondary data from a crosssectional questionnaire.

\section{Participants}

Participants were healthcare professionals (of any cadre) with past experience of international placements or those due to depart on an international placement in the near future. Participants self-identified their own past 
experience as an international placement and there was no limit on how recent the experience must have been.

\section{Procedure}

The original data were collected from opportunistic sample and participants were recruited either online or face-to-face ${ }^{30}$ Full details of the procedure are published elsewhere. ${ }^{30}$ In summary, face-to-face participants were recruited using an opportunity sample at health professional events nationwide, many of which had an international focus (the majority of the sample gained this way were of nurses). Online participants were recruited in numerous ways, including links to the questionnaire posted on international volunteering blogs and in health professional newsletters and bulletins (online supplementary file 1 has a comprehensive list of the recruitment methods used with each anonymised collaborating organisation). The majority of the online sample were gathered using a network technique. Organisations, projects and hospital health links that place professionals internationally agreed to send the link via email to health professionals and the majority of the doctors responded online.

The questionnaire elicited responses from those with past volunteering experience about their most recent experience, whereas those due to depart responded to three questions about behaviours they expect to exhibit that have been considered negative in past literature (working outside of competence, comfortable working in high risk situations and using annual leave).

\section{Measures}

The questionnaire was developed based on a systematic review and meta-synthesis of 55 peer-reviewed papers to identify any reported potential negative outcomes of health professional international placements in low-income and middle-income countries and the full methods are presented elsewhere. ${ }^{4}$ In this review negative outcomes were extracted from the peer-reviewed literature and meta-synthesised this with qualitative data gathered during stakeholder workshops a list of 33 negative outcomes that can be found in online supplementary file 1.

Twenty-one items were measured on a 7-point Likert scale, tick boxes or free-text (see table 1). These items were developed from the 33 negative outcomes extracted in the systematic review. ${ }^{4}$ Negative outcomes that could not be tested using self-assessment because they were outcomes for organisations, not individuals, were not included in the questionnaire. Those due to depart (pre-placement) were asked three unique questions in relation to negative outcomes. Many of the items were developed in order to measure the absence of something that is considered a cost, for example, recognition and accreditation. The questionnaire was piloted with a team of researchers to access readability ${ }^{30}$. Table 1 outlines each item and how it was presented and online supplementary file 1 shows the paper version of the items in the questionnaire.
Table 1 Presentation of items in questionnaire

\begin{tabular}{lll}
\hline Item & Presentation & Questionnaire \\
\hline $\begin{array}{l}\text { Lost interest in profession } \\
\text { because of placement }\end{array}$ & Likert & Post \\
$\begin{array}{l}\text { Want to leave NHS because } \\
\text { of placement }\end{array}$ & Likert & Post
\end{tabular}

Unable to cope with UK Likert Post
paperwork because of
placement

Experienced health Tick Post

consequences (injuries,

illness, and so on)

\begin{tabular}{|c|c|c|}
\hline Loss of earnings & Tick & Post \\
\hline Loss of pension & Tick & Post \\
\hline Exposure to corruption & Tick & Post \\
\hline $\begin{array}{l}\text { Informal recognition from } \\
\text { seniors }\end{array}$ & Tick & Post \\
\hline $\begin{array}{l}\text { Informal recognition from } \\
\text { colleagues }\end{array}$ & Tick & Post \\
\hline
\end{tabular}

\begin{tabular}{lll} 
Formal recognition & Tick & Post \\
\hline Accreditation & Tick & Post \\
$\begin{array}{l}\text { No recognition or } \\
\text { accreditation }\end{array}$ & Tick & Post \\
\hline
\end{tabular}

\begin{tabular}{lll}
$\begin{array}{l}\text { Involved in returners' } \\
\text { scheme/help back to work/ } \\
\text { support on reintegration }\end{array}$ & Tick & Post \\
$\begin{array}{l}\text { Employment on return: } \\
\text { (locum/agency/bank work) }\end{array}$ & Tick & Post \\
$\begin{array}{l}\text { Overall the experience was: } \\
\text { (positive/negative/neutral) }\end{array}$ & Tick & Post \\
$\begin{array}{l}\text { Financial cost (high=more } \\
\text { than £2000/low=less than } \\
£ 2000 / \text { no financial cost) }\end{array}$ & Free Text & Post \\
$\begin{array}{l}\text { Skills applicable to current } \\
\text { stage in career }\end{array}$ & Tick & Post \\
$\begin{array}{l}\text { Skills applicable to UK } \\
\text { position }\end{array}$ & Tick & Post \\
$\begin{array}{l}\text { Skills not applicable to } \\
\text { current stage in career or UK } \\
\text { position }\end{array}$ & Tick & Post \\
\hline
\end{tabular}

Comfortable to work outside Likert Pre

competence

\begin{tabular}{ll}
$\begin{array}{l}\text { Comfortable to work in high- } \\
\text { risk situations }\end{array}$ & Pre \\
Used annual leave for trip $\quad$ Tick & Pre \\
\hline
\end{tabular}

NHS, National Health Service.

\section{Demographic variables}

We collected data about five demographic variables: age, gender, nationality, year of registration (to represent career stage) and staff group (nine categorical items: allied health professionals; healthcare scientists; medical and dental; NHS infrastructure support; other scientific, 
Table 2 Professional cadres of participants

\begin{tabular}{lll}
\hline Staff group & $\begin{array}{l}\text { Returned } \\
\text { volunteers } \\
(\mathbf{n}=\mathbf{1 6 9 )}\end{array}$ & $\begin{array}{l}\text { Due to } \\
\text { depart } \\
(\mathbf{n}=53)\end{array}$ \\
\hline Medical and dental & 77 & 29 \\
\hline Nursing and midwifery & 51 & 13 \\
\hline Allied health professionals & 23 & 6 \\
\hline Healthcare scientists & 6 & 1 \\
\hline Ambulance & 2 & 0 \\
\hline NHS infrastructure support & 1 & 0 \\
\hline $\begin{array}{l}\text { Other scientific, therapeutic } \\
\text { and technical }\end{array}$ & 8 & 4 \\
Other & 1 & 0 \\
\hline
\end{tabular}

NHS, National Health Service.

therapeutic and technical; qualified ambulance staff; registered nursing, midwifery and health visiting staff; support to clinical staff and other). These categories are representative of NHS staffing groups and have been used in past research in the field. ${ }^{31}$ Data were also collected regarding the nature of the placements: destination country and length of stay (using open text responses).

\section{Analysis}

Frequency of data is reported as number of participants and percentage of the sample. As this is a secondary analysis of data, the sample size is based on guidelines for principle component analysis, the primary purpose of this data collection. ${ }^{30} 32$

\section{RESULTS}

\section{Participants}

In total there were 222 participants, of these 169 (76\%) had past international experience and were asked about their most recent experience. Fifty-three were due to depart on an international placement $(24 \%)$, so they were asked about behaviours they expect to exhibit (which have been considered negative outcomes in past research). Online supplementary file 1 shows the demographic information for each group and table 2 demonstrates the professional cadres of the sample. Tables 3 and 4 show the length of the placements in the sample and the countries visited and highlights the variation in participant placements.

\begin{tabular}{ll}
\hline Table 3 Length of placement \\
\hline Length of stay & $\begin{array}{l}\text { Number and percentage of } \\
\text { participants }\end{array}$ \\
\hline Short: less than 2 months & $76(45 \%)$ \\
Medium: 2 to 11 months & $47(28 \%)$ \\
Long: 12 months or more & $30(18 \%)$ \\
Missing data & $16(9 \%)$ \\
\hline
\end{tabular}

Table 4 Destination countries: destinations reported by two or more people; there were 50 destinations in total

\begin{tabular}{ll}
\hline Country & Number and percentage of participants \\
\hline Uganda & $37(22 \%)$ \\
Sierra Leone & $17(10 \%)$ \\
\hline Malawi & $10(6 \%)$ \\
Nepal & $8(5 \%)$ \\
\hline Kenya & $8(5 \%)$ \\
\hline Tanzania & $6(4 \%)$ \\
\hline Ethiopia & $6(4 \%)$ \\
Afghanistan & $5(3 \%)$ \\
\hline Bangladesh & $5(3 \%)$ \\
Cambodia & $4(2 \%)$ \\
\hline South Sudan & $4(2 \%)$ \\
Ghana & $4(2 \%)$ \\
\hline Botswana & $3(2 \%)$ \\
\hline South Africa & $3(2 \%)$ \\
\hline Thailand & $2(1 \%)$ \\
\hline Myanmar & $2(1 \%)$ \\
\hline Zambia & $2(1 \%)$ \\
China & $2(1 \%)$ \\
\hline India & $2(1 \%)$ \\
\hline Malaysia & $2(1 \%)$ \\
\hline Egypt & $2(1 \%)$ \\
\hline & \\
\hline
\end{tabular}

\section{Frequency of negative outcomes}

The results provided an indication of the frequency that negative outcomes happen. Some of the outcomes were experienced by the majority of participants: lack of formal recognition $(131 / 169,77.8 \%)$, lack of accreditation $(168 / 169,99.4 \%)$ and a financial cost $(92 / 169$, $68.1 \%)$. While others happened less frequently: a reliance on agency or locum work $(12 / 169,7.1 \%)$, loss of pension $(31 / 169,18.3 \%)$, health consequences $(26,15.1 \%)$ and loss of interest in profession $(18 / 169,10.8 \%)$. In general $94.1 \%(159 / 169)$ reported that the experience overall was positive.

\section{Negative financial outcomes}

In terms of actual financial cost, for $32 \%(43 / 135)$ there was no cost at all, the majority spent less than $£ 2000$ $(104 / 135,77 \%)$ and $23 \%(31 / 135)$ spent over $£ 2000$. More distal indicators of financial cost also happened relatively infrequently that only $18 \%(31 / 169)$ reported a loss of pension and 32\% (66/169) reported a loss of earnings. Of those that completed the pre-departure questionnaire, $42 \%$ (22/169) reported using annual leave to take the trip.

\section{Negative impact on recognition and accreditation}

Only one participant received formal accreditation while 99\% (168/169) did not. However, most received informal recognition from colleagues $(109 / 169,64 \%)$ and about 
half received informal recognition from seniors $(75 / 169$, $44 \%)$. Formal recognition was reported by $22 \%(38 / 169)$ of sample, while $23 \%(39 / 169)$ reported no recognition or accreditation at all.

\section{Return to the UK}

When staff returned to the UK, only $7 \%(12 / 169)$ relied on locum or agency or bank work, but on the other hand, only $8 \%(13 / 169)$ were involved in an official programme that supported the transition. In terms of their UK position, 36\% (61/169) reported feeling unable to cope with NHS paperwork on return. A loss of interest in one's profession as a result of the placement was reported by $11 \%(18 / 169)$. A third of the participants reported wanting to leave the NHS because of their placement $(60 / 169,36 \%)$.

\section{Exposure}

Almost one-third of the participants reported being exposed to corruption $(50 / 16930 \%)$, but only $15 \%$ (26/169) reported a health consequence.

\section{Skills}

From an educational perspective, 32\% (54/169) of participants believed that the skills they gained were not applicable to their UK position. It was reported by $25 \%$ $(42 / 169)$ that the skills gained were not applicable to their current career stage. Only $11 \%(18 / 169)$ found that skills were applicable to neither their current career stage nor their UK position.

\section{Pre-departure expectations}

Before departure almost half of the participants reported feeling comfortable working outside of their competence on their upcoming trip $(26 / 53,49 \%)$. A similar amount also reported feeling comfortable working in high-risk situations $(30 / 53,57 \%)$. Almost half of the participants due to depart were doing so using their annual leave $(22 / 53,42 \%)$, see table 5 .

\section{DISCUSSION}

We found, in a convenience sample of UK health professionals, that some negative outcomes were experienced by most healthcare professionals, including lack of recognition and impact on accreditation. Others, although reported, were less frequent, including health consequences and exposure to corruption.

The outcomes reported in this research quantify some of the concerns that have been raised in previous literature. It has been argued that students risk working outside of their competence in LMICs; which has dangerous consequences for both the students and the local patients. ${ }^{33}$ This research has highlighted equally how important this issue is with a professional population, as before departure $49.1 \%$ felt comfortable working outside of their competence on their upcoming trip. This research also quantifies the extent of this problem, it indicates that about half of potential volunteers would be happy to work outside their competence. This finding highlights the importance of education regarding the potentially problematic ethical, emotional and professional implications for health professionals. A similar finding suggests that $56 \%$ felt comfortable working in a high-risk situation in their upcoming placement where this could be indicative of the positive, selfless character of staff that choose to undertake volunteering, but it could also highlight the unpreparedness of some healthcare professionals and thus the necessity to implement future training about risk, competence and ethical implications.

Previous studies have quantified the health consequences of short-term volunteers; however, this was not specific to healthcare professionals. It found $9.6 \%$ of participants accessed medical care and that 'diarrhoea' was the most frequently reported health consequence by $24 \%$ of the population. ${ }^{23}$ These findings are similar suggesting that $15 \%$ of the health professional sample experienced some sort of health consequence (anything from insect bites to traffic accidents). Having this information readily available to prospective volunteers and their employers would allow them to predict and mitigate risks associated with volunteering.

Inadequate recognition and accreditation have been reported as both a negative outcome and a barrier for participation. ${ }^{47}$ However, it has been argued that certain trusts are particularly good at formally and informally supporting international work, through health partnerships, for example. ${ }^{34}$ This research provides quantification of the extent of this problem, but also highlights the successes of some trusts. It indicates that formal accreditation is extremely rare and only one participant in the sample received this; whereas, $64 \%$ reported informal recognition from colleagues. This study also highlights that the recognition is lower among senior colleagues and happens less frequently, as less than half (43\%) reporting recognition from that professional group. This highlights the need for further education among health professionals and managerial staff of the personal and professional development (PPD) benefits of international work.

Employers, some professionals and some policymakers argue that skills developed on international placement are of little use to the individual or the NHS. ${ }^{133}$ Either because the participants are too junior to use the knowledge, skills and attitudes developed (i.e., leadership) or that there is a disconnect between the skills developed in LMICs and high-income countries' systems and equipment. ${ }^{11}{ }^{14}$ While this research does not refute this argument, it provides a level of quantification, as $32 \%$ stated that the skills developed were not relevant to their UK position and $25 \%$ stated that the skills were not relevant to their career stage. It is however encouraging that around two-thirds felt the skills were relevant to their position and career stage, indicating that extra efforts should be made to facilitate decisions around relevant placements. However, this can only be achieved when professional learning in LMIC environments is better understood. 
Table 5 The percentage of participants that reported each negative outcome

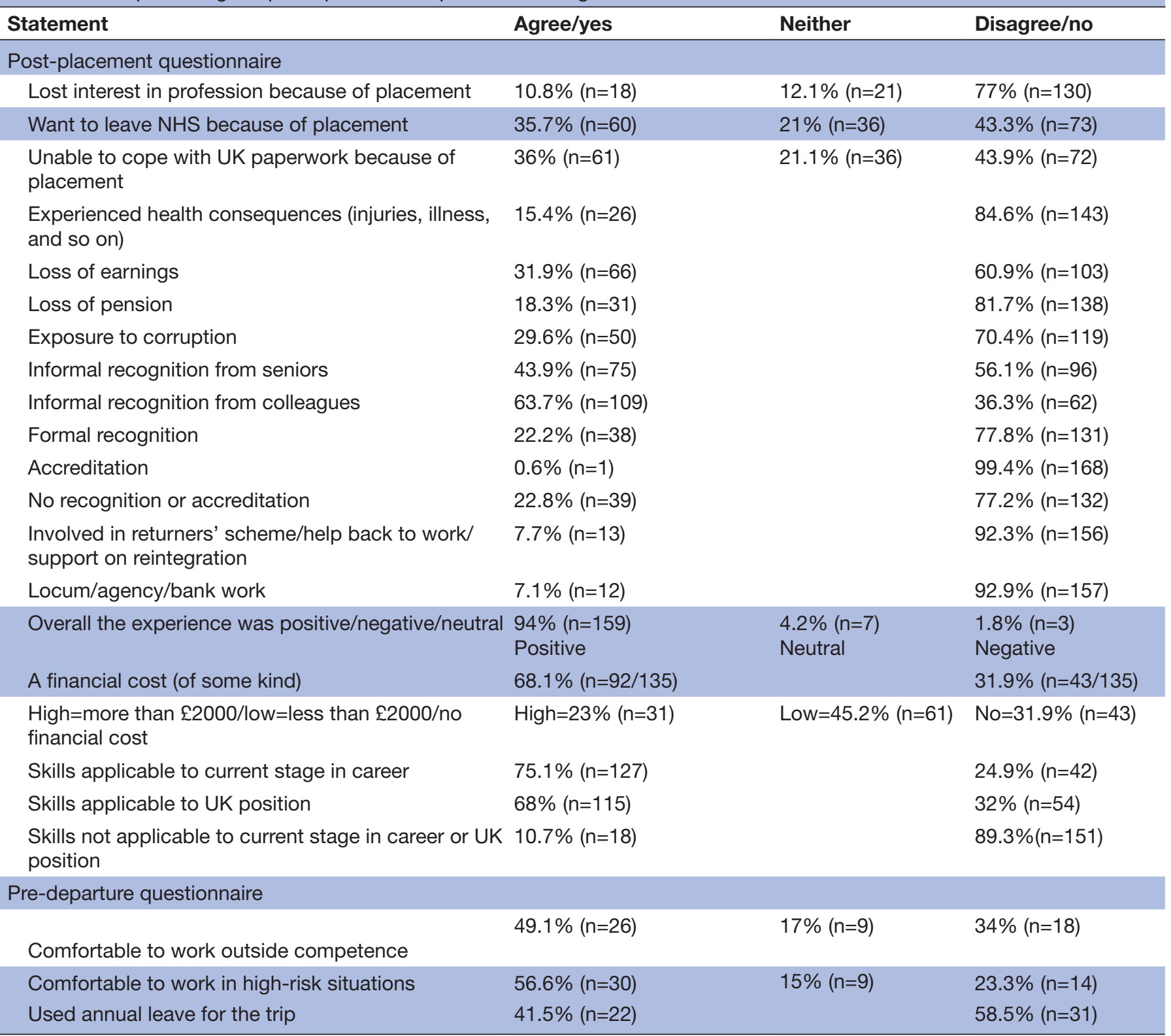

NHS, National Health Service.

This study is relevant and useful to policymakers, employers and individual healthcare professionals interested in international placements. By outlining all of the reported potential negative outcomes in the literature and reporting an estimation of their occurrence, groups could make better decisions about placements, weighing up the pros and cons. In time, this list of negative outcomes could be used to collect prospective data, in which benefits and negative outcomes are assessed and balanced. Assessing and measuring negative outcomes associated with particular types of placement could also help placement providers and individual healthcare professionals understand how negative outcomes occur and make attempts to avoid them.

For policymakers this study presents some findings that could be used to help facilitate healthcare professionals to undertake international placements within an NHS system. For example, almost all of the sample reported no accreditation, meaning there are options for Royal Colleges/employers/universities to explore this, given the growing body of literature evidencing the personal and professional benefits of such work for both individuals and organisations. ${ }^{13-5}$ It also highlights the lack of informal recognition received, something which could be more easily implemented by organisation or professional bodies. This research also quantifies something that has been widely identified as a barrier to international placements: ${ }^{520}$ the use of annual leave for such activity. Around one-third of the participants used their annual leave for their placement. There is a growing body of literature highlighting burn out in healthcare professionals and how it may affect patient safety. ${ }^{35}$ If already burnt out 
staff use their relaxation time to continue working, this could also have knock-on effects on patient care and performance. Research suggests that international placements are associated with a wide range of personal and professional development, ${ }^{13-5}$ as this paper provides quantification of how often annual leave might be used for this activity and it provides further justification for developing alternative methods of release to allow staff to partake in this activity.

This work and relevant previous work ${ }^{40}$ provides a framework to allow future researchers to measure the factors that are associated with positive or negative outcomes and potentially find ways to reduce or mitigate them for future volunteers. Due to the sampling limitations of this study, future research should look to replicate these results with a more purposeful sample, then use the framework of negative outcomes to begin to assess differences between the numerous different types of placements.

The policy direction of WHO and the Department for International Development is towards all active UK engagement occurring within established 'partnerships'. ${ }^{29} 37$ This work provides a framework of potential negative outcomes; which could be used in future research to compare the positive and negative outcomes of partnerships with other volunteering options, to potentially provide quantitative evidence. With future advancements of measurement in this field, a data set could be available to indicate which placements (ie, country, town, provider) are associated with which benefits and which potential risks/negative outcomes, to allow volunteers, educators and employers to make informed decisions. Future research may consider categorising the health consequences from less severe and temporary (diarrhoea, non-infectious insect bites) to fatalities or debilitating accidents.

Although we tested the questionnaire for readability and acceptability, we aimed to ascertain whether people have experienced something, rather than trying to assess/measure a hypothetical construct, therefore the questionnaire was not validated. There are limitations to the conclusions that can be drawn from this study. Our sampling strategy was not representative, therefore these results are only indicators from this sample rather than direct estimates of how common these negative outcomes appear in the whole population of health professions in international placements. These were post hoc analyses so there were no planned comparisons, therefore our findings are only suggestive of hypotheses that need to be tested and not hypothesis testing themselves. However, the demographic data suggest that participants varied in terms of their professional group, age, gender and experience levels. There is also evidence that there was a spread of types of experience, as participants varied in terms of length of stay and country visited, (only three countries were visited by 10 or more participants). Similarly, the framework of negative outcomes extracted from the literature is developed from literature outlining varied projects. ${ }^{4}$ Second, we can only comment on UK health professionals and not on those from other countries, who might have different experiences. Further research is needed to test the applicability of these findings to other international volunteers. Third, there is a potential that recall bias may have an effect on the results as some participants returned to the UK many years ago and may not have recollected details sufficiently. Finally, it must also be noted that the definition of negativity is context specific dependant on perspective and open to interpretation, for example, it might be argued that leaving UK to work in a more disadvantaged environment is a positive outcome.

\section{CONCLUSION}

There were a range of negative outcomes from volunteering in literature and these varied in terms of how frequently they were experienced, in a convenience sample of UK health professionals. Assessing negative outcomes alongside positive ones will enable policymakers, employers and health professionals to weigh up the pros and cons of placements. Further research should consider these outcomes in a representative sample of the UK healthcare professional volunteer population and also compare different types of placement for negative outcomes. This will enable us to understand how negative outcomes occur and suggest ideas for how to prevent them.

Our findings imply that there are some negative outcomes from international volunteering that are experienced by a majority of health professionals. There are likely to be certain types of placements which are associated with more negative outcomes. Future research should consider assessing negative outcomes and their association with features of volunteering experiences. Policymakers and those who place international volunteers should be aware of the common negative outcomes and attempt to guard against them.

Twitter Natasha Tyler @DrNatashaTyler, Ged Byrne @gedbyrne and Lucie ByrneDavis @luciebd

Acknowledgements The full title of the study from which this analysis was derived was: Measuring the outcomes of volunteering for education (MOVE). The study was funded by Health Education England (Global Health Exchange). The research team were independent from the funding agency. The views expressed in this publication are those of the authors and not necessarily those of Health Education England or the Department of Health.

Contributors NT participated in the design of the study, conducted the pilot and drafted the majority of the manuscript. LBD conceived the design of the study, analysed data and contributed significantly to drafting the manuscript. HLA, AA and GB participated in the coordination of the research and contributed to the manuscript.

Funding This work was supported by a project development grant from Health Education England (HEE), through the Global Health Exchange (GHE); grant reference, NURA54.

Competing interests Professor GB is the Director of Global Engagement for Health Education England. The other authors declared no competing interests.

Patient and public involvement Patients and/or the public were not involved in the design, or conduct, or reporting or dissemination plans of this research. 
Patient consent for publication Not required.

Ethics approval Approval for the study was obtained from the Ethical Research Committee, University of Salford and the University of Manchester Research Ethics Committee. Participants gave informed consent. The procedures followed were in accordance with the ethical standards of the Helsinki Declaration (1964, amended most recently in 2008) of the World Medical Association.

Provenance and peer review Not commissioned; externally peer reviewed. Data availability statement Data are available upon reasonable request.

Open access This is an open access article distributed in accordance with the Creative Commons Attribution Non Commercial (CC BY-NC 4.0) license, which permits others to distribute, remix, adapt, build upon this work non-commercially, and license their derivative works on different terms, provided the original work is properly cited, appropriate credit is given, any changes made indicated, and the use is non-commercial. See: http://creativecommons.org/licenses/by-nc/4.0/.

ORCID iD

Natasha Tyler http://orcid.org/0000-0001-8257-1090

\section{REFERENCES}

1 Ackers HL, Ackers-Johnson J, Chatwin J, et al. Healthcare, Frugal innovation, and professional Voluntarism. Cham: Springer International Publishing, 2017.

2 Baguley D, Killeen T, Wright J. International health links: an evaluation of partnerships between health-care organizations in the UK and developing countries. Trop Doct 2006;36:149-54.

3 Tropical Health Education Trust. In our mutual interest, 2017.

4 Tyler N, Chatwin J, Byrne G, et al. The benefits of international volunteering in a low-resource setting: development of a core outcome set. Hum Resour Health 2018;16:69.

5 Jones FA, Knights DP, Sinclair VF, et al. Do health partnerships with organisations in lower income countries benefit the UK partner? A review of the literature. Global Health 2013;9:38.

6 Crisp N. Mutual learning and reverse innovation--where next? Global Health 2014;10:14.

7 Leather AJM, Butterfield C, Peachey K, et al. International health links movement expands in the United Kingdom. Int Health 2010;2:165-71.

8 Connolly AM, Stirling S. Working in a developing country. which is good experience. BMJ 1995;311:946.

9 Young P, Smith C, Pettigrew L, et al. International work and leadership in UK general practice. Leadersh Health Serv 2014;27:87-103.

10 Seo H-N, Smith C, Pettigrew LM, et al. Combining UK general practice with international work--who benefits? Br J Gen Pract 2012;62:e726-8.

11 Kiernan P, O'Dempsey T, Kwalombota K, et al. Evaluation of effect on skills of GP trainees taking time out of programme (OOP) in developing countries. Educ Prim Care 2014;25:78-83.

12 Briscoe L. Becoming culturally sensitive: a painful process? Midwifery 2013;29:559-65.

13 Gilbert BJ, Miller C, Corrick F, et al. Should trainee doctors use the developing world to gain clinical experience? The annual Varsity
Medical Debate - London, Friday 20th January, 2012. Philos Ethics Humanit Med 2013;8:1.

14 Abell C, Taylor S. The NHS benefits from doctors working abroad. BMJ 1995;311:133-4.

15 Lee ACK, Hall JA, Mandeville KL. Global public health training in the UK: preparing for the future. J Public Health 2011;33:310-6.

16 Banatvala N, Macklow-Smith A. Integrating overseas work with an NHS career. BMJ 1997;314:bmj.314.7093.2:2.

17 Lumb A, Murdoch-Eaton D. Electives in undergraduate medical education: AMEE guide No. 88. Med Teach 2014;36:557-72.

18 Evans R, Dotchin C, Walker R. Maximising the value from the elective experience: post-elective workshops. Clin Teach 2013;10:362-7.

19 Greatrex-White S. Uncovering study abroad: foreignness and its relevance to nurse education and cultural competence. Nurse Educ Today 2008;28:530-8.

20 Dean E. 'Tanzania changed me'. Nurs Stand 2013;27:16-17.

21 Smith C, Pettigrew LM, Seo H-N, et al. Combining general practice with international work: online survey of experiences of UK GPs. JRSM Short Rep 2012;3:1-8.

22 Button L, Green B. The impact of international placements on nurses' personal and professional lives: literature review. J Adv 2005

23 Wyler N, Green S, Boddington N, et al. Travel related illness in shortterm volunteers from the UK to developing countries. Travel Med Infect Dis 2012;10:172-8.

24 Elnawawy O, Lee ACK, Pohl G. Making short-term international medical volunteer placements work: a qualitative study. $\mathrm{Br} J$ Gen Pract 2014;64:e329-35.

25 Dowell J, Merrylees N. Electives: isn't it time for a change? Med Educ 2009;43:121-6.

26 Morgan DA. Student nurse perceptions of risk in relation to international placements: a phenomenological research study. Nurse Educ Today 2012;32:956-60.

27 Chatwin J, Ackers L. Organisational barriers to the facilitation of overseas volunteering and training placements in the NHS. BMC Health Serv Res 2018;18:69.

28 Ackers HL. SVP policy report: the importance of Volunteer/Health worker relationships to project outcomes. Salford, 2014.

29 Dfid. Health partnership scheme evaluation synthesis report, 2016.

30 Tyler N, Collares C, Byrne G, et al. Measuring the outcomes of volunteering for education: development and pilot of a tool to assess healthcare professionals' personal and professional development from international volunteering. BMJ Open 2019;9:e028206.

31 Chatwin J, Ackers L. Volunteering and overseas placements in the NHS: a survey of current activity. BMJ Open 2016;6:e012160.

32 Charter RA. Sample size requirements for precise estimates of reliability, generalizability, and validity coefficients. J Clin Exp Neuropsychol 1999;21:559-66.

33 Banatvala N, Doyal L. Knowing when to say "no" on the student elective. Students going on electives abroad need clinical guidelines. BMJ 1998;316:1404-5.

34 Longstaff B. How international health links can help the NHS workforce develop. Health Serv J 2012.

35 Panagioti M, Geraghty K, Johnson J, et al. Association between physician burnout and patient safety, professionalism, and patient satisfaction: a systematic review and meta-analysis. JAMA Intern Med 2018;178:1317.

36 Hall LH, Johnson J, Watt I, et al. Burnout, and patient safety: a systematic review. PLoS One 2016;11.

37 Crisp N. Global health partnerships, 2007. 